\title{
Effect of Dance Aerobic Programs on Intrinsic Motivation and Perceived Task Climate in Secondary School Students
}

\section{Stella Rokka}

Assoc. Prof., corresponding author, Department of Physical Education and Sport Science, Democritus University of Thrace, Komotini, Greece, srokka@phyed.duth.gr

\section{Olga Kouli}

Asst. Prof., Department of Physical Education and Sport Science, Democritus University of Thrace, Komotini, Greece, okouli@phyed.duth.gr

\section{Evangelos Bebetsos}

Assoc. Prof., Department of Physical Education and Sport Science, Democritus University of Thrace, Komotini, Greece, empempet@phyed.duth.gr

\section{Dimitrios Goulimaris}

Assoc. Prof., Department of Physical Education and Sport Science, Democritus University of Thrace, Komotini, Greece,dgoulima@phyed.duth.gr

\section{George Mavridis}

Asst. Prof., Department of Physical Education and Sport Science, Democritus University of Thrace, Komotini, Greece, mavridig@phyed.duth.gr

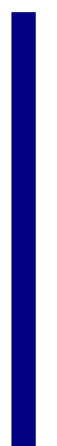

The aim of the present study was to investigate the effect of a dance aerobic intervention program on intrinsic motivation and perceived motivation climate in 7 th grade middle school students. The sample of the study consisted of 160 healthy students, of the first grade of middle school. Of these, 91 students was the experimental group and the remaining 69 was the control. The experimental group followed an aerobic dance intervention program for ten weeks, three times per week, with 45-minute sessions while the control group only followed the typical physical education program of the school. In order to conduct the study the following instruments were used: a) the Intrinsic Motivation Inventory (IMI McAuley, Duncan \& Tammen, 1989) and the Perceived Oriented Climate (LAPOPECQ; Papaioannou, 1998).

Keywords: enjoyment, task involving climate, aerobic dance program, seventh grade students, teaching

Citation: Rokka, S., Kouli, O., Bebetsos, E., Goulimaris, D., \& Mavridis, G. (2019). Effect of Dance Aerobic Programs on Intrinsic Motivation and Perceived Task Climate in Secondary School Students. International Journal of Instruction, 12(1), 641-654. https://doi.org/10.29333/iji.2019.12141a 


\section{INTRODUCTION}

School represents an ideal environment for the promotion of physical activity among young people. It is accessible for the majority of the Greek population and it provides facilities, trained personnel and a study schedule that considers public health (Hills, Dengel, \& Lubans, 2015). The ulterior target of PE as a subject is to shape behaviors and attitudes that will encourage students to deal with physical activity for the rest of their lives (Alderman et al., 2006).

Despite the above allegations, there are studies supporting that students do not include intense or even moderate physical activity in their lives, which would have multiple benefits for their health (Lonsdale et al., 2013; Fairclough \& Stratton, 2005). The more youngsters grow up, the less they exercise. In fact, this diminution begins even during school years (Papaioannou et al., 2004) and it becomes evident especially in adolescence, which is a transitive period (Biddle et al., 2004; Currie et al., 2008). This alteration coincides with attitudes concerning adaptation motives in school and in the context of PE in particular (Ntoumanis et al., 2009).

This gradual and dramatic reduction of interest in the subject of PE from primary to senior high school is indicative of the lack of motivation, which is a crucial factor for the students' active participation in the lesson (Owen et al., 2014; Yli- Piipari, 2011). Lonsdale and co-authors (2009) conducted an investigation which recorded that students who had an intrinsic motivation in a subject were $20 \%$ more active than students who had an extrinsic motivation in the same subject (e.g., pressure from others). Likewise, Jaakkola et al., (2008) confirmed that intrinsic motivation was a definitive factor for a moderate or vigorous physical activation in the context of PE.

The motivation climate during a PE lesson is connected to the students' perceptions about goal achievement, which is also sought by PE teachers as a proper learning environment (Ames, 1992). A task-involving motivational climate is connected with high internal motivation, interest, cooperation, effort, intense realization of the utility of the subject of PE, active participation and tendency for participation in later physical activities (Ames \& Archer, 1988; Escartí \& Gutiérrez, 2001; Hein \& Müür, 2004). On the contrary, an ego-involving motivational climate has negative effects on interest and enjoyment, since students occupy themselves displaying their skills and try to achieve maximum results with minimum effort, feeling embarrassed when they fail (Dweck \& Leggett, 1988). As a result, they may stop trying after a series of unsuccessful efforts, because they cannot feel accomplished surpassing the others (Duda \& Balaguer, 2007; Duda, 1996; Goudas \& Biddle, 1994).

PE teachers who create a task learning climate during the lesson will probably influence their students positively as concerns their orientation to learning and they will also increase their effort to participate in the lesson actively and take up out-of-school physical activity later (Barkoukis et al., 2008; Cox et al., 2008; Digelidis et al., 2003). Duda and Nicholls (1992), while investigating the achievement goals of high school students, they found that a task orientated climate was connected with the students' perception that the lesson was attractive and interesting. This climate seems to urge 
students to try harder (Lonsdale et al., 2009). A research by Vira and Raudsepp (2002) showed that the feeling of enjoyment/interest is one of the most significant factors for the students to continue aerobic exercise moderately or even intensely. Nowicki and his colleagues (2004) found that only 23, 5\% of the students who participated in their research took up PE lesson because they found it enjoyable or interesting. Sallis, Prochaska and Taylor (2000) revealed that students' enjoyment was a strong prediction factor for their active participation in a PE lesson, especially for those aged 4 to 6 and between 7 to 12 years old. Pleasant PE lessons encourage students to be more active in various environments of physical activity (Hagger, 2014). Thus, enjoyment in the subject of PE plays an essential role in the further occupation of students with physical exercise (Garcia Bengoechea et al., 2010).

In Greece various researches (Digelidis, Papaioannou, 1999; Papaioannou, 1997) indicated that children in elementary school appear to be more task orientated in PE classes and as they grow and move from elementary to junior and senior high school, they lose their intrinsic motivation, become less task-orientated and as a result they feel less competent and do not participate in classes. Many studies support that the students' pleasure and effort in the subject of PE is gradually reduced during high school (Papaioannou, 1997) and thus, their active participation should be examined with greater responsibility. Diggelidis and Papaioannou (2004) confirmed that the participants of their research, aged 10 to 17, both tried and enjoyed themselves less during the PE lessons and supported that there may be considerable deficiencies in the current PE school programs, which should be more attractive and interesting, proposing new challenging skills.

Dance aerobic has been very popular in recent decades, because it is a group exercise, which is enjoyable and non competitive (Podrigalo et al., 2016). Popular dance aerobic often resembles dance therapy, although the sport refers to a general public rather than patients or professional athletes. It is rather its strong sense of rhythm and movement that appeals to a greater number of people (Ciomag \& Dinciu, 2013). Aerobic dance classes emphasize coordination and cooperation between movement and modern pop music.

When an individual is fully immersed in music, it can experience the perfect combination of body and soul through limb movements and in coordination with music. Actually, a dance aerobic class is a form of adolescents' social integration in modern society which can also influence the image of students' bodies positively as well as their feeling of self-esteem and their awareness that physical exercise is important for their health (Majeed, 2015).

Studies which applied dance aerobic programs on students aged 8-12 have shown the positive effects of dance aerobic on health-related physical abilities (Aldemir et al., 2011; Ignico \& Mahon, 1995; Mavridis et al., 2004) and that students accept such programs easily and with pleasure (Kremenitzer, 1990). Mandarić, Sibinović and Stojiljković (2011) used a sample of 31 females, with an average age of 14, and divided it into two groups (experimental $n=16$ and control $n=15$ ), in order to estimate the effect of high-low dance aerobics on the morphological characteristics, as well as the 
functional and kinetic abilities. The intervention program lasted for eight weeks, and was carried out during regular PE classes. The results showed that the changes observed, after the application of the program, were statistically significant in connection with the morphological features as well as the functional and kinetic abilities of the participants. In one of their studies, Pelclová and his colleagues (2008), using a sample of 241 girls from three junior high schools with a mean age $16.0 \pm 1.6$ years, claimed that dance aerobic lessons can be an effective tool to enhance physical activity interest during PE lessons.

Aerobic dance can motivate students to deal with and maintain physical activity in later life and seem to be very influential in a course of PE lessons. Burgess, Grogan and Burwitz (2006) examined the effect of a 6-week dance aerobics program on the physical self-perception of adolescent girls. The results showed that practicing dance aerobic exercises for six weeks enhanced their physical self perception significantly. Bartholomew and Miller (2002) supported that participating in dance aerobic classes can be very beneficial. Dance aerobics programs seem to be an activity which could be quite effective in promoting cardio respiratory fitness and health benefits of physical activity in school-aged children and youth (Blagojević, et al., 2017; Janssen \& LeBlanc, 2010; Mavridis et al., 2004).

Based on the above bibliography, the authors of the present study can assume that the use of an educational dance aerobics program will increase the interest, the effort and the enjoyment of its participants and will have a positive influence on the creation of a motivational climate among students of the first grade of secondary school. It is of great significance to explore the possibilities of establishing new programs in order to develop the intrinsic motivation and perceived climate of students in secondary schools during the PE classes.

Therefore, the purpose of the present study was to investigate the influence of a dance aerobic intervention program, on 'intrinsic motivation' and 'perceived motivation climate', for secondary school students during PE classes.

\section{METHOD}

\section{Sample}

The sample of the study consisted of 160 healthy students, of the first grade of secondary school, aged 12 and $13(\mathrm{M}=12.6, \mathrm{SD}=0.4)$. Of these, 91 students was the experimental group ( 46 boys and 45 girls) and the remaining 69 students was the control group (32 boys and 37 girls). The experimental group followed an aerobics dance intervention program, while the control group only followed the school's physical education curriculum.

\section{Measurements}

Intrinsic Motivation. To measure intrinsic motivation, the questionnaire used was the IMI (Intrinsic Motivation Inventory, McAuley, Duncan, \& Tammen, 1989), which consists of 18 questions and includes 4 factors. For the purpose of the study, only the 8 questions that formed the two factors were used to measure a) Interest - Enjoyment and b) Effort, as they were modified for the Greek population by Diggelidis and Papaioannou (1999). The Interest - Enjoyment scale consists of four items (e.g. “... I 
enjoy the PE lesson very much"), and the Effort scale comprises four items (e.g. "...I try hard while I practice"). Following the stem "In this Physical Education class..." responses were given on a five-point Likert-type scale from 1 (Strongly Disagree) to 5 (Strongly Agree).

Perceived Motivational Climate. In order to measure the students' perceptions of the motivational climate created by their PE teacher in the lesson, the short version of the Learning and Performance Orientations in Physical Education Classes Questionnaire (LAPOPECQ) (Papaioannou, 1994; Papaioannou, 1998; Papaioannou, et al., 2004) was used. This short version contains 13 items assessing two basic factors of motivational climate, that is "task involving climate" and "ego involving climate". The task involving climate consists of 7 items (e.g. "...the Physical Education Teacher pays attention especially how I am improving during the activities"), and the ego involving climate comprises of 6 items (e.g. "...the Physical Education Teacher pays attention only to the best performances"). Following the stem "In this Physical Education class..." responses to the items were given on a five-point Likert-type scale rating from 5 (Strongly Agree) to 1 (Strongly Disagree). This instrument has been used successfully in the longitudinal study of Marsh and his colleagues (2006) and in several studies with Greek students (Barkoukis et al., 2007; 2008).

\section{Intervention program and procedure}

The initial and final evaluation of the elements related to intrinsic motivation and perceptions of students of the motivational climate created by their PE teacher was carried out within the school environment. The questionnaire was anonymous and filled in during the first (initial measurement) and the tenth (final measurement) week in class.

After the initial measurements, the experimental group followed the aerobic dance program. Intervention program was performed for 10 weeks, two sessions per week and each session lasted 45 minutes. Every lesson included 10 min warm up with stretch moves and music was played at a soft rhythm, 20 - 25 min continuous aerobic dance exercises, $10 \mathrm{~min}$ muscular strength exercises and finally up to $5 \mathrm{~min}$ cool down included relaxation exercises with slow rhythm music. The intensity of the main program was $60 \%-75 \%$ of the maximum heart rate (music $130-135$ beats per minute) in the first four weeks. After four weeks, the intensity was increased to $75 \%-85 \%$ of the maximum heart rate (music 140-150 beats per minute) from the fifth to eight week. In the next two weeks the intensity of the program was reduced to $60 \%-70 \%$ of the maximum heart rate. The experimental group attended the dance aerobic intervention program under the instructions of a physical education teacher, who was professional dance aerobics instructor (Master's student at the Department of the Physical Education and Sport Sciences of the Democritus University of Thrace). The control group attended typical physical education classes (athletic instruction content) as prescribed by the National Curriculum for PE classes of the Ministry of Education of the Greece. None of the students involved in additional strenuous training during this study out of school.

\section{FINDINGS}

The means and standard deviations for each of the four factors, for the initial and final measurements, are reported in Table 1. The mean scores ranged from 2.74 to 4.05 with 
'Enjoyment' revealing the highest mean score and 'ego involving climate' the lowest mean score. The Cronbach's alpha was used and indicated that the items used to measure the constructs were reliable. More specifically, reliability analyses showed that all factors had an acceptable level of internal consistency. As is shown in Table 1, for all factors, the reliability alpha coefficients were .74 or above (Cronbach, 1951).

Table 1

Reliability analysis and descriptive statistics of the factors of the two questionnaires, at the initial and final measurements.

\begin{tabular}{lllllll}
\hline Measures & Initial & & & Final & \\
\hline Factors & M & SD & $\begin{array}{l}\text { Cronbach's } \\
\text { Alpha }\end{array}$ & M & SD & $\begin{array}{l}\text { Cronbach's } \\
\text { Alpha }\end{array}$ \\
\hline $\begin{array}{l}\text { Intrinsic Motivation } \\
\begin{array}{l}\text { 1. Enjoyment } \\
\text { 2. Effort }\end{array}\end{array}$ & 3.85 & 0.63 & .74 & 4.05 & 0.72 & .78 \\
\hline $\begin{array}{l}\text { Perceived Motivational } \\
\text { Climate }\end{array}$ & 3.78 & 0.78 & .75 & 3.89 & 0.76 & .76 \\
Task involving climate & 3.84 & 0.65 & .76 & 4.00 & 0.64 & .77 \\
Ego involving climate & 3.01 & 0.70 & .77 & 2.74 & 0.85 & .77 \\
\hline
\end{tabular}

\section{Correlations}

Pearson Correlation analyses were conducted among the intrinsic motivation and the perceived motivation climate factors, at the initial and final measurements (Table 2). More specifically, the correlations analysis indicated that 'Enjoyment' was significantly and positively associated with 'Effort' (pre $r=.40 ; \mathrm{p}<.01$ / post $\mathrm{r}=.63 ; \mathrm{p}<.01$ ), and 'Task involving climate'(pre $\mathrm{r}=.43 ; \mathrm{p}<.01 /$ post $\mathrm{r}=.56 ; \mathrm{p}<.01$ ), but no relationship was observed with 'Ego involving climate'(pre $\mathrm{r}=-.01 ; \mathrm{p}>.05 /$ post $\mathrm{r}=-.06 ; \mathrm{p}>.05$ ), at the initial and final measurement.

Also, the results revealed that 'Effort' had a statistically significant relationship with 'Task involving climate' (pre $\mathrm{r}=.35 ; \mathrm{p}<.01 /$ post $\mathrm{r}=.54 ; \mathrm{p}<.01$ ), but no relationship was observed with 'Ego involving climate' (pre $\mathrm{r}=.07 ; \mathrm{p}>.05 /$ post $\mathrm{r}=.02 ; \mathrm{p}>.05$ ), at the initial and final measurement. Finally, the 'Task involving climate'had no relationship with 'Ego involving climate' (pre $r=-.00 ; \mathrm{p}>.05 /$ post $\mathrm{r}=.03 ; \mathrm{p}>.05$ ), at the initial and final measurement.

Table 2

Pearson correlations coefficients for each factor at the initial and the final measurement.

\begin{tabular}{|c|c|c|c|c|c|c|c|c|}
\hline Measures & Initial & & & & Final & & & \\
\hline Factors & 1 & 2 & 3 & 4 & 1 & 2 & 3 & 4 \\
\hline \multicolumn{9}{|l|}{ Intrinsic Motivation } \\
\hline 1. Enjoyment & 1.00 & & & & 1.00 & & & \\
\hline 2. Effort & $.40 * *$ & 1.00 & & & $.63 * *$ & 1.00 & & \\
\hline \multicolumn{9}{|l|}{ Perceived Motivation Climate } \\
\hline 3. Task involving climate & $.43 * *$ & $.35^{* *}$ & 1.00 & & $.56^{* *}$ & $.54 * *$ & 1.00 & \\
\hline 4. Ego involving climate & -.01 & .07 & -.00 & 1.00 & -.06 & .02 & .03 & 1.00 \\
\hline
\end{tabular}

Note: significant $* *=p<.01$ 


\section{Gender Differences at the initial measurement}

At the beginning, the Independent t-test analysis was held to find out if there were statistically significant differences between the boys and girls at the initial measurement. The results showed that there were not statistically significant differences in the 'enjoyment' $\left[\mathrm{t}_{(160)}=.441 ; \mathrm{p}>.05\right.$; (boys $\mathrm{M}=3.83 \& \mathrm{SD} .72$; girls $\mathrm{M}=3.84 \&$ SD .54)], 'effort' $\left[\mathrm{t}_{(160)=.9} 948 ; \mathrm{p}>.05\right.$; (boys $\mathrm{M}=3.74 \& \mathrm{SD} .79$; girls $\mathrm{M}=3.81 \& \mathrm{SD} .68$ )], 'task

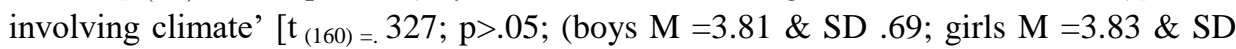
$.62)]$, and 'ego involving climate' $\left[\mathrm{t}_{(160)}=1.63\right.$; $\mathrm{p}>.05$; (boys $\mathrm{M}=3.07 \& \mathrm{SD} .74$; girls $\mathrm{M}$ $=2.92 \&$ SD .72)] factors. Therefore, the boys and girls presented about the same values in the above four factors.

Differences between experimental and control group at the initial measurement

Also, the Independent t-test analysis was applied to check whether there were any statistically significant differences in the questionnaire factors between the experimental and the control group at the initial measurement. From the results it appeared that any differences in the 'enjoyment' $\left[\mathrm{t}_{(160)}=-.109 ; \mathrm{p}>.05\right]$, 'effort' $\left[\mathrm{t}_{(160)}=-.233 ; \mathrm{p}>.05\right]$, 'task involving climate' $\left[\mathrm{t}_{(160)}=-.121 ; \mathrm{p}>.05\right]$, and 'ego involving climate' $\left[\mathrm{t}_{(160)}=-.380\right.$; p>.05], factors were not statistically significant.

\section{Differences in intrinsic motivation}

Then, the Anova Repeated measures analysis was applied for the "enjoyment" and "effort" factors. The analysis model (2X2) included the variable "measurement" (initial - final) as the repetition variable and the variable "group" (experimental - control) as the independent variable.

The results showed that there was a statistically significant interaction between the variables "measurement" and "group" for "enjoyment' $\left[F_{(1,158)}=8.98, p<.01, \eta^{2}=.05\right]$ with the post-hoc test showing that the experimental group improved its average score after the intervention program, while the control group remained stable. As for the factor 'effort' the results revealed that there was a statistically significant interaction between the variables "measurement" and "group" $\left[\mathrm{F}_{(1,158)}=15.61, \mathrm{p}<.001, \eta^{2}=.09\right]$ with the post-hoc test showing that the experimental group improved, while the control group reduced the mean scores after the end of the program. The means, standard deviations and the analytical differences between experimental and control group, are shown in Table 3 .

\section{Differences in perceived motivation climate}

Finally, the Anova Repeated measures analysis was applied for the "task involving climate" and "ego involving climate" factors. The analysis model (2X2) included the variable "measurement" (initial - final) as the repetition variable and the variable "group" (experimental - control) as the independent variable.

The results indicated that there was a statistically significant interaction between the variable "measurement" and "group" for the "task involving climate" $\left[F_{(1,158)}=6.55\right.$, $\left.\mathrm{p}<.05, \eta^{2}=.04\right]$ with the post-hoc test showing that the experimental group improved its 
average score after the intervention program, while the control group remained unaltered. Also, for the "ego involving climate" factor the results revealed that there was a statistically significant interaction between the variable "measurement" and "group" [F $\left.(1,158)=9.82, \mathrm{p}<.01, \eta^{2}=.06\right]$ with the post-hoc test showing that the experimental group reduced its score while the control group remained stable. The means, standard deviations and the analytical differences between experimental and control group, are shown in Table 3.

Table 3

Means and Standard Deviation of the experimental and control group at the initial and final measurement.

\begin{tabular}{|c|c|c|c|c|c|c|}
\hline \multirow{2}{*}{ Variables } & \multirow{2}{*}{ Team } & Initial & \multicolumn{3}{|c|}{ Final } & \multirow{2}{*}{$\begin{array}{l}\text { Measurement/ Group } \\
\text { Interaction }\end{array}$} \\
\hline & & $\mathrm{M}$ & SD & $\mathrm{M}$ & SD & \\
\hline \multirow{2}{*}{ Enjoyment } & Experimental & 3.86 & .59 & $4.23 * *$ & .71 & \multirow{2}{*}{$\begin{array}{l}F_{(1,158)}=8.98, p<.01 \\
\eta^{2}=.05\end{array}$} \\
\hline & Control & 3.83 & .68 & 3.82 & .67 & \\
\hline \multirow{2}{*}{ Effort } & Experimental & 3.77 & .67 & $4.09 * * *$ & .71 & \multirow{2}{*}{$\begin{array}{l}F_{(1,158)}=15.61, p<.001, \\
\eta^{2}=.09\end{array}$} \\
\hline & Control & 3.80 & .79 & 3.63 & .75 & \\
\hline \multirow{2}{*}{$\begin{array}{l}\text { Task involving } \\
\text { climate }\end{array}$} & Experimental & 3.85 & .63 & $4.12 *$ & .57 & \multirow{2}{*}{$\begin{array}{l}F_{(1,158)}=6.55, p<.05 \\
\eta^{2}=.04\end{array}$} \\
\hline & Control & 3.83 & .69 & 3.82 & .68 & \\
\hline \multirow{2}{*}{$\begin{array}{l}\text { Ego involving } \\
\text { climate }\end{array}$} & Experimental & 2.99 & .67 & $2.56^{* *}$ & .73 & \multirow{2}{*}{$\begin{array}{l}F_{(1,158)}=9.82, p<.01, \\
\eta^{2}=.06\end{array}$} \\
\hline & Control & 3.03 & .74 & 2.97 & .94 & \\
\hline
\end{tabular}

Note 1: M=Mean Prices, S.D. =Standard Deviations of the factors

Note 2: significant $* * * p<.001, * * p<.01, * p<.05$.

\section{DISCUSSION}

The present study investigated the intrinsic motivation and perceived motivation climate levels of students aged twelve to thirteen, before and after the application of an aerobics dance intervention program. The specific program was chosen as a means of improving intrinsic motivation for students of the first grades of secondary school because they were glad to participate (Mandaric et al., 2011). Aerobic dance is a group entertaining exercise, which is enjoyable and non competitive and it is also a form for young people to integrate in modern society (Ciomag et al., 2013). Moreover, such programs contribute to pupils' cognitive and emotional development and significantly ameliorate kinetic skills, which are considered essential for the establishment of a kinetic basis for pupils of secondary school (Ferdowsi et al., 2010; Kriventsova et al., 2017).

As concerns the correlation analyses among the factors of the two questionnaires, the results showed that enjoyment and effort have a positive statistic relation with a task involving climate. On the contrary, an ego involving climate is not related with any of the intrinsic motivation factors. The results of the present study are consistent with the findings of Papaioannou (1995), who confirmed that the perceived task-involving motivational climate in PE lessons had a significant positive correlation with intrinsic motivation, interest, enjoyment in lessons and intention for high levels of effort. In addition, there are researches confirming that the factor effort increases, when students find the lesson interesting and pleasant and results in their trying harder (Cox et al., 2008; Lonsdale et al., 2009). 
After the realization of the dance aerobics program, the results showed a statistically significant increase in the factor enjoyment (initial mean $=3.86$, final $=4.23$ ), effort (initial mean $=3.77$, final $=4.09$ ) and perceived task involving climate (initial mean $=3.85$, final $=4.12$ ) and a parallel reduction in the factor ego involving climate (initial mean $=2.99$, final $=2.56$ ). Aerobic dance classes emphasize coordination and cooperation between movement and modern pop music. When an individual is fully immersed in music, he/she can experience the perfect combination of body and soul through limb movements and in coordination with music. This also influences the students' image of their bodies positively as well as their feeling of enjoyment and their awareness that physical exercise is important for their health (Ciomag et al., 2013).

Dance aerobic is a pleasant, entertaining way of exercising for both adults and adolescents. Through dance aerobic, school students can enrich their kinetic repertoire and improve their physical skills, which are related to health (Kremenitzer, 1990; McIllroy et al, 1989). They can also increase their self confidence (Alpert, Field, Goldstein \& Perry, 1990) and develop their cognitive and emotional condition.

Very few dance aerobic programs have been designed in order to investigate the relation between intrinsic motivation and task involving climate, in respect to $1^{\text {st }}$ grade secondary school students. Most existing studies have examined the influence of dance aerobics on physical skills, ignoring the fact that students' motivation is an important, even decisive factor for their participating actively in PE classes. Lonsdale and coauthors (2013) showed that students who were intrinsically motivated were $20 \%$ more active than students with external motivation. Similar researches concerning the subject of PE in school, reported that the most important factor for active participation in class and later occupation with physical activity is the pleasure taken during a PE lessons (Subramanian \& Silverman, 2007). Also, Roberts (1992) working with children and adolescents supported that desire for enjoyment and pleasure is one of the dominant reasons for participating in PE classes. A research by Vira and Raudsepp (2002) conducted on adolescents showed that young people regard pleasure and motivation as one of the most significant factors for their continuing practicing moderate or intense dance aerobic.

The application of a dance aerobic intervention program, as shown by the findings of the experimental group, increased intrinsic motivation, something which was expressed with the increase in interest, enjoyment and effort. Also, in a study by Kouli, Rokka, Mavridis and Derri (2009), the results showed that a dance aerobic program enabled students aged 10 to 11 to improve all health-related abilities, as well as their intrinsic motivation, in an easy, enjoyable way. These findings are in accordance with those of McIlloy et al. (1989), who supported that the use of dance aerobic is a non-competitive, entertaining activity, which improves health-related fitness and intrinsic motivation. On the contrary, participating only in a typical PE program seems inadequate to achieve the above goals. According to Gabbard (1990), the first half of a PE class should be dedicated to dance aerobic, a complex activity which develops endurance, muscular strength, and flexibility and rhythm coordination. 
The results of the present study are particularly important, considering the fact that both Greek and international researches show that participation in PE classes seems to decline, as students grow older (Armstrong et al., 2007; Bauman et al., 2009; Digelidis et al. 2003). Previous studies supported that level of daily moderate-to-vigorous Physical Activity (MVPA) declines particularly during adolescence (Corbin et al., 2004; Currie et al., 2008). Secondary School years represent a critical period in the development of physical activity patterns that extend to adulthood. When PE schedules are attractive and pleasant focusing on learning through participation and effort they increase students' interest and motivate them to carry on exercising.

\section{CONCLUSION}

Finally, the application of a dance aerobic program is easy for PE teachers to design and enjoyable for students to apply. It can be supported that today, the application of such programs is crucial due to the modern way of living, which is characterized by the absence of adequate kinetic activity. Moreover, it could be used as a preventive measure against potential disorders, since today's unhealthy children are tomorrow's potential adult patients. Thus, it is probable that dance aerobic activities can affect a large number of Secondary School students to include regular physical activity in their adult lives. A better understanding of the role of motivational climate may promote children's and adolescents' perceived physical competence, intrinsic motivation, and enjoyment through PE classes.

\section{REFERENCES}

Adams, M. A., Johnson, W. D., Tudor-Locke, C. (2013). Steps/day translation of the moderate-to-vigorous physical activity guideline for children and adolescents. Int $J$ Behav.Nutr. Phys Act., 10, 49. https: //doi. org/10.1186/1479-5868-10-49.

Albert, B., Field, T., Goldstein, S., \& Perry, S. (1990). Aerobic Enhances Cardiovascular Fitness And Agility in Preschoolers. Health Psychology, 9, 48-56.

Aldemir, G.Y., Ramazanoğlu, N., Çamlıüney, A. F., \& Kaya, F. (2011). The effects of dance education on motor performance of children. Educational Research and Reviews, 6(19), 979-982.

Alderman, B., Beighle, A., \& Pangrazi, R. (2006). Enhancing motivation in physical education. Journal of Physical Education, Recreation, and Dance, 77(2), 41-45.

Ames, C., \& Archer, J. (1988). Achievement goals in the classroom: Students' learning strategies and motivation processes. Journal of Educational Psychology, 80(3), 260267.

Ames, C. (1992). Achievement goal, motivational climate, and motivational processes. In G. Roberts (Ed.) Motivation in Sport and Exercise (pp. 161-176). Champaign, IL: Human Kinetics.

Armstrong, N., \& Welsman, J. R. (2007). Physical activity patterns of European youth with reference to methods of assessment. Sports Medicine, 36, 1067-1086.

Barkoukis, V., Thøgersen-Ntoumani, C., Ntoumanis, N., \& Nikitaras, N. (2007). Achievement goals in physical education: Examining the predictive ability of five 
different dimensions of motivational climate. European Physical Education Review, 13, 267-272.

Barkoukis, V., Tsorbatzoudis, H., \& Grouios, G. (2008). Manipulation of motivational climate in physical education: Effects of a 7-month intervention. European Physical Education Review, 14, 376-387.

Bartholomew, J. B., \& Miller, B. M. (2002). Affective responses to an aerobic dance class: The impact of perceived performance. Research Quarterly for Exercise and Sport, 73(3), 301-309.

Bauman, A., Bull, F., Chey, T., Craig, C. L., Ainsworth, B. E., Sallis, J. F., Bowles, H. R., Hagstromer, M., Sjostrom, M., \& Pratt, M. (2009). The international prevalence study on physical activity: Results from 20 countries. International Journal of Behavioral Nutrition and Physical Activity, 6, 1-11.

Biddle, S., Gorely, T., \& Stensel, D. (2004). Health-enhancing physical activity and sedentary behavior in children and adolescents. Journal of Sports Sciences, 22/8, 679701.

Burgess, G., Grogan, S., \& Burwitz, L. (2006). Effects of a 6 week aerobic dance intervention on body image and physical self-perceptions in adolescent girls. Body image, 3(1), 57-66.

Gabbard, C. (1990). Health-related fitness. Curricular formats for elementary physical formats for elementary physical education. Strategies, 14-18.

Ciomag, R.-V., \& Dinciu, C.-C. (2013). Aerobics - Modern Trend in the University Educational Domain. Procedia - Social and Behavioral Sciences, 92, 251-258. https://doi.org/10.1016/j.sbspro.2013.08.668.

Corbin, C. B., Pangrazi, R. P., Le-Masurier, G. C. (2004). Physical activity for children: Current patterns and guidelines. The President's Council of Physical Fitness and Sports Research Digest, 52, 1-8.

Cox, A. E., Smith, A. L., Williams, L. (2008). Change in physical education motivation and physical activity behavior during middle school. Journal of Adolescent Health, 43, 506-513.

Cronbach, L. J. (1951). Coefficient alpha and the internal structure of tests. Psychometrika, 16, 297-334.

Currie, C., Gabhainn, S. N., Godeau, E., Roberts, C., Smith, R., Picket, W., Barnekow, V. (2008). Inequalities in young people's health. Health behaviour in school-aged children. International report from the 2005/2006 survey. Available from URL: http://www.euro. who.int/ data/assets/ pdf_file/0005 /53852/ E91416.pdf

Diggelidis, N., \& Papaioannou, A. (1999). Age group differences in intrinsic motivation, goal orientations and perceptions of athletic competence, physical appearance and motivational climate in Greek physical education. Scandinavian Journal of Medicine and Science in Sports, 9,375-380. 
Digelidis, N., Papaioannou, A., Laparidis, K., Christodoulidis, T. (2003). A one-year intervention in 7 th grade physical education classes aiming to change motivational climate and attitudes towards exercise. Psychology of Sport and Exercise, 4(3), 195210 .

Duda, J. L., \& Nicholls, J. G. (1992). Dimensions of achievement motivation in schoolwork and sport. Journal of Educational Psychology, 84, 290-299.

Duda, J. L. (1996). Maximizing motivation in sport and physical education among children and adolescents: the case for greater task involvement. Quest, 48, 290-302.

Duda, J. L., \& Balaguer, I. (2007). Coach-created motivational climate. Social psychology in sport. Jowett S., Lavallee D., editors. Champaign, IL: Human Kinetics; 117-13.

Dweck, C. S., \& Leggett, E. L. (1988). A social-cognitive approach to motivation and personality. Psychological Review, 95/2, 256-273.

Escartí, A., \& Gutiérrez, M. (2001). Influence of the Motivational Climate in Physical Education on the Intention to Practice Physical Activity or Sport. European Journal of Sport Science, 1(4), 1-12.

Fairclough, S., \& Stratton, G. (2005). Physical activity levels in middle and high school physical education: A review. Pediatric Exercise Science, 17/3, 217-236.

Ferdowsi, M., Marashian, F., \& Marashian, S. (2010). The Effects of 12-Week Aerobic Exercises on Rate of Mental Health in Male Students of Ahvaz Payam Noor University. Human Movement, 11(2),167-71.

Gabbard, C. (1990). Health-related fitness. Curricular formats for elementary physical formats for elementary physical education. Strategies, 14-18.

Garcia Bengoechea, E., Sabiston, C., Ahmed, R., \& Farnoush, M. (2010). Exploring links to unorganized and organized physical activity during adolescence: The role of gender, socioeconomic status, weight status, and enjoyment of physical education. Research Quarterly for Exercise and Sport, 81(1), 7-16.

Goudas, M., \& Biddle, S. J. H. (1994). Perceived Motivational Climate and Intrinsic Motivation in School Physical Education Classes. European Journal of Psychology of Education, 9, 241-50.

Gråstén, A., Jaakkola, T., Liukkonen, J., Watt, A., \& Yli-Piipari, S. (2012). Prediction of Enjoyment in School Physical Education. J Sports Sci Med., 11(2), 260-269.

Gülay Yasemin Aldemir, Nusret Ramazanoğlu, Asiye Filiz Çamlıüney and Fatih Kaya (2011). The effects of dance education on motor performance of children. Educational Research and Reviews, 6(19), 979-982.

Hagger, M. (2014). An integrated multi-theory model to explain the processes of motivational transfer across contexts. Doctoral thesis, University of Jyväskylä.

Hein, V., \& Müür, M. (2004). The Mediating Role of Cognitive Variables between Learning Oriented Climate and Physical Activity Intention. International Journal of Sport and Exercise Psychology, 35, 60-76. 
Hills, A. P., Dengel, D. R., \& Luban, D. R. (2015). Supporting Public Health Priorities: Recommendations for Physical Education and Physical Activity Promotion in Schools. Progress in Cardiovascular Diseases, 57, 368-374.

Jaakkola, T., Liukkonen, J., Ommundsen, Y., Laakso, T. (2008). The relationships between situational and contextual self-determined motivation and physical activity intensity as measured by heart rates during ninth grade students' physical education classes. European Physical Education Review, 14, 13-31.

Jaakkola, T., Washington, T., Yli-Piipari, S. (2013). The association between motivation in school physical education and self-reported physical activity during Finnish junior high school: The self-determination theory approach. European Physical Education Review, 19, 127-141.

Kouli, O., Rokka, S., Mavridis, G., Derri, V. (2009). The effect of an aerobic program on health-related fitness and intrinsic motivation on elementary school pupils. Studies in Physical Culture and Tourism, 16(3), 301-306.

Kremenitzer, P. J. (1990). Aerobic Fitness Dancing in the Elementary Schools. Journal of Physical Education, Recreation and Dance, 61, 89-90.

Kriventsova, I., Pashkevych, S., Iermakov, S., Bartík, P., Michal, J., Nosko, M., \& Yermakova, T. (2017). Fitness - aerobic training of 15 -17 years' age girl students, who have significant risk of deviations in backbone functional state. Journal of Human Sport and Exercise, 12(4), 1289-1297. doi: https: //doi. org/ 10.14198 /jhse. 2017.124.15

Lonsdale, C., Rosenkranz, R. R., Sanders, T., Peralta, L. R., Bennie, A., Jackson, B., Taylor, I. M., \& Lubans, D. R. (2013). A cluster randomized controlled trial of strategies to increase adolescents' physical activity and motivation in physical education: Results of the Motivating Active Learning in Physical Education (MALP) trial. Preventive Medicine, 57(5), 696-702. doi: doi:10.1016/j.ypmed. 2013.09.003

Liukkonen, J., Barkoukis, V., Watt, A., \& Jaakkola, T. (2010). Motivational climate and students' emotional experiences and effort in physical education. The Journal of Educational Research, 103, 295-308.

McAuley, E., Duncan, T., \& Tammen, V. V. (1989). Psychometric properties of intrinsic motivation inventory in a competitive sport setting: A confirmatory factor analysis. Research Quarterly of Exercise and Sport, 60, 48-58.

McIllroy, H. B., Roundy, S. E., \& Jacobson, C. P. (1989). A Progressive Aerobic Program for Elementary Aged Children. The Physical Educator, 46, 21-26.

Mavridis, G., Filippou, F., Rokka, S., Bousiou St., \& Mavridis, K. (2004). The effect of a health-related aerobic dance program on elementary school children. Journal of Human Movement Studies, 47, 337-349.

Nader, P. R., Bradley, R. H., Houts, R. M., McRitchie, S. L., \& O’Brien, M. (2008). Moderate-to-vigorous physical activity from ages 9 to 15 years. JAMA, 300, 295-305. doi:10.1001/jama.300.3.295

Nicholls, J. (1984). Achievement motivation: Conceptions of ability, subjective experience, task choice, and performance. Psychological Review, 91(3), 328-346. 
Nicholls, J. (1989). The competitive ethos and democratic education. Cambridge, MA: Harvard University Press.

Nowicki, S., Duke, M. P., Sisney, S., Stricker, B., \& Tyler, M. A. (2004). Reducing the drop-out rates of at-risk high school students: The effective learning program (ELP). Genetic, Social, and General Psychology Monographs, 130(3), 225.

Ntoumanis, N., \& Standage, M. (2009). Motivation in physical education classes: A self-determination theory perspective. Theory and Research in Education, 7(2), 194202.

Owen, K. B., Smith, J., Lubans, D. R, Ng J. Y, Lonsdale, C. (2014). Self-determined motivation and physical activity in children and adolescents: A systematic review and meta-analysis. Prev Med., 67, 270-279.

Papaioannou, A. (1994). The development of a questionnaire to measure achievement orientations in Physical Education. Research Quarterly for Exercise and Sport, 65, 11-20.

Papaioannou, A. (1997). Perception of motivational climate, perceived competence and motivation of students of varying age and sport experience. Perceptual \& Motor Skills, 85, 419-430.

Papaioannou, A. (1998). Students' Perceptions of the Physical Education Class Environment for Boys and Girls and the Perceived Motivational Climate. Research Quarterly for Exercise and Sport, 69(3), 267-275.

Papaioannou, A., Marsh, H.W., Theodorakis, Y. (2004). A multilevel approach to motivational climate in physical education and sport settings: an individual or a group level construct. J. Sport Exerc. Psychol., 26, 90-118.

Pelclová, J., Fröme, K., Skalik, K., Stratton, G. (2008). Dance and aerobic dance in physical education lessons: the influence of the student's role on physical activity in girls. Acta Univ. Palacki. Olomuc., Gymn, 38(2), 85-92.

Podrigalo, L.V., Iermakov, S. S., Alekseev, A. F., \& Rovnaya, O. A. (2016). Studying of interconnections of morphological functional indicators of students, who practice martial arts. Physical Education of Students, 1, 64-70. https://doi.org / 10.15561/20755 279/2016.0109.

Roberts, G.C, \& Treasure, D.C (1992). Children in sport. Sport Science Review, 1(2), 46-64.

Subramanian, P. R., \& Silverman, S. (2007). Middle school students' attitudes toward physical education. Teaching and Teacher Education, 23, 602-611.

Vira, R., \& Raudsepp, L. (2002). Associations between socio-psychological determinants and physical activity in grade 7 through 8. Kehakultuurite aduskonna teadus ja oppemetoodiliste toode kogumik, 165-178.

Yli-Piipari, S. (2011). The development of students' physical education motivation and physical activity - A 3.5-year longitudinal study across Grades 6 to 9. Doctoral thesis, University of Jyvaskyla. p,170. 